\title{
Inspection Violations and Community Care Facilities in British Columbia, Canada.
}

Tony Yip ${ }^{1}$, Helen Heacock ${ }^{2}$, Bobby Sidhu ${ }^{3}$, Lorraine McIntyre ${ }^{4}$

1. Leader Author, B.Tech Candidate in Environmental Health, British Columbia Institute of Technology, 3700 Willingdon Avenue, BC V5G 3H2

2. Supervisor, School of Health Sciences, British Columbia Institute of Technology, 3700 Willingdon Avenue, BC V5G 3H2

3. Contributor, British Columbia Institute of Technology, 3700 Willingdon Avenue, BC V5G 3H2

4. Contributor, British Columbia Centre for Disease Control, 655 West $12^{\text {th }}$ Avenue, Vancouver, BC V5Z 4R4

\begin{abstract}
:
Background: In British Columbia, community care facility is a broad term that covers many different type of facilities including residential care and child care facilities. These facilities are inspected and audited by the BC regional health authorities to ensure that they are operating in compliance with the BC Community Care and Facilities Act and its respective regulations. These facilities house population groups that are at higher risk of injury or illness due to their physiology and behaviour. Therefore, it is crucial that these facilities are operating in compliance with the prescribed legislation to minimize the risk of illness and injury to the users of these facilities.
\end{abstract}

Objective: The purpose of this study was to determine if there were any differences in the number of violations in residential care and child care facilities between the different health authorities in BC.

Methods: Inspection data were randomly selected and extracted from each of BC's five health authority's websites and assessed for the number of violations found in these inspections. Violations were tallied and an ANOVA analysis was performed to identify if there were any differences in the number of violations between the health authority regions.

Results: Statistical analysis was performed using Microsoft Excel 2013 and NCSS. There was a statistically significant difference of violations between child care and residential care facilities located in the Interior Health Authority region and Northern Health Authority region. Interior Health Authority child care and residential care facilities have more violations than Northern Health Authority child care and residential care facilities.

Conclusion: Violations in child care and residential care facilities varied among the five BC HA region. The IHA facilities were found to have the overall highest number of violations for both child care and residential care facilities whereas the NHA facilities were found to have the lowest number of violations. This suggests that patrons of child/residential care facilities in IHA have a higher potential of getting injured or ill compared to patrons in facilities located in NHA.

Keywords: Community care licensing facilities, child care, licensing officer, environmental health officer, EHO, LO, residential care, inspections, violations 


\section{INTRODUCTION:}

In British Columbia (BC), Canada, there are five regional health authorities (HA) in charge of various inspection programs such as water systems, food establishments, recreational water facilities, community care and assisted living facilities. These inspection and violation reports were recently made accessible on the internet for the public's viewing. Facilities located and inspected in the Vancouver Coastal Health (VCH) region have their inspection reports accessible at www.vch.ca. Fraser Health Authority (FHA) region inspections are viewable on their website at www.fraserhealth.ca. Vancouver Island Health Authority (VIHA) inspection reports can be found at www.viha.ca. Interior Health Authority (IHA) inspections are located at www.interiorhealth.ca and Northern Health Authority (NHA) inspections are locating at www.northernhealth.ca. In 2014, an investigation was performed by Cseke et al. that examined inspection violation data of food service establishments in the FHA region to assess if there were any differences in violations made among ethnic, non-ethnic and chain restaurants (2014). This was the first known analysis on violation rates among different food establishments in BC. It was found that ethnic restaurants reported to have higher occurrences of violations compared to non-ethnic and chained restaurants in the FHA region. This result indicated that there is a need to pool resources into educating ethnic-restaurant operators on proper food handling procedures to minimize the occurrence of violations in ethnic food establishments.

Similar to food establishments, community care and assisted living facilities are also licensed and inspected by the regional HAs. However, unlike food premises, community care and assisted living facilities are inspected and licensed by Licensing Officers (LO), which are delegated this power by the Medical Health Officer (MHO). These facilities must abide to the $B C$ Community Care and Assisted Living Act (BCCCALA) and its regulations (2008). Inspections reports at these facilities are also published onto the HAs' website for public viewing. As these facilities house and care for the very young, old, and immunocompromised, which are at greater risk of becoming ill or injured, the British Columbia Centre for Disease Control is interested in analyzing the trend of violation data found in these inspections among VCH, FHA, VIHA, IHA and NHA regions.

Acts and Regulations: BC Community Care and Assisted Living Act

In $\mathrm{BC}$, the $B C$ Community Care and Assisted Living Act $(B C C C A L A)$ is the legislated framework that establishes a minimum standard for safeguarding the health, safety, and dignity of residents being cared for in these facilities. A mandatory minimum health and safety level is established and provides the legal authority to respond to complaints. A delegated individual, usually the LO, is responsible for the licensing, inspecting for compliance with the established legislations, and enforcing these legislations. Most importantly, this legislation gives the LO, whom is delegated by the $\mathrm{MHO}$, the power to inspect community care facilities, child care facilities, and other facilities that are prescribed under the BCCALA. An important part of this act is that it prescribes the rights of the individuals who are being cared for in their facility. The Schedule within the BCCALA act outlines the commitment to care, rights to health, safety, and dignity, rights to participation and freedom of expression, rights to transparency and accountability, and scope of rights. This act outlines the procedures to initiate a complaint should a patron feel that their rights have been violated. Furthermore, this act outlines the provisions that protects the patrons from, but not limited to, being evicted, denied a right, or discharged (B.C. Laws, 2002). The rights of these individuals may be infringed upon, however the frequency of these occurrences is not summarized in the individual inspection reports.

\section{BC Community Care and Assisted Living Regulation}

This BC regulation outlines the different meanings of "prescribed services" that is used in section 1 and section 34(4)(a) of the BCCCALA. These services include:

- Assistance with daily living such as eating, moving, dressing, grooming, bathing and personal hygiene

- Storing, distributing, administering and monitoring of medication

- Maintaining and managing cash resources and other property of the person in care

- Monitoring person's diet and ensure they are following prescribed therapeutic diets

- Structured behavior management and intervention

- Psychological rehabilitation/intensive rehabilitation therapy

This regulation also prevents the MHO from exempting anyone from the above mentioned services. If an appeal is required to be made to the board of appeal, it must be done in writing. Furthermore, this regulation outlines that the $\mathrm{LO}$ or $\mathrm{MHO}$ can request a warrant to enter a single private family home via telephone or any other means of telecommunication (B.C. Laws, 2008).

\section{BC Residential Care Regulation}


The BC Residential Care Regulation (BCRCR) covers care for adults who are in need of the following:

- Hospice care for people in need of short-term palliative services for care at the end of their lives

- Care for mental disorders, substance dependence or both

- Long term care for people with chronic and/or progressive conditions.

- Community living care for people with developmental disabilities

- Acquired injury care for people who are physically, intellectually, and cognitively impaired due to injury such as brain injuries or injuries from accidents (B.C. Laws, 2013c)

As the above list suggests, these facilities house people for long-term care that are classified as a high-risk group population. This population is more prone to contracting infections and injuries due to their medical conditions, physical age, and chronic diseases. As a result, these individuals may require other's assistance throughout their daily life. The BCRCR extensively prescribes many of the operations required by these licensed facilities from vast documentations, having a prescribed care plan, physical activity plan and more. Inspections are performed on the basis of the following categories to ensure compliance with the BCRCR:

- Care and/or supervision

- Hygiene and communicable disease control

- Licensing

- Medication

- Nutrition and food services

- Physical facility, equipment and furnishings

- Policies and procedures

- Program

- Records and reporting

- Staffing (Fraser Health Authority, 2012; Vancouver Coastal Health Authority, n.d.[b], Vancouver Island Health Authority, n.d.)

\section{BC Child Care Licensing Regulation}

Child care facilities are one type of community care and assisted living facilities. The $B C$ Child Care Licensing Regulation (BCCCLR) establishes the legislative standards in running child care facilities. These are defined as facilities that operate programs for three or more children that are not blood related to the operator. The regulation prescribes nine types of child care facilities that require licensing under the BCCCLR: Group child care for children under 36 months; group child care for children 30 months to school age, preschool children 30 months to school age, group child care for school age children, multi-age child care, family child care, in-home multi-age care, occasional child care, and child-minding (Vancouver Coastal Health, n.d.[a]). Under section 4(1)(e), the licensing director can specify standards for community care facilities to practise and follow (B.C. Laws, 2013a). Under the BC Ministry of Health, a Safe Play Space Standard of Practice was developed in 2007. This standard of practice is enforceable by the LOs and outlines the safety standards and precautions needed for a play space (BC Ministry of Health, 2007). In 2008, the standards of practice for family child care was placed into effect. This standard of practice established that family child care facilities must provide an environment to nurture social, emotional, physical and intellectual growth of children. The facilities are required to have rooms similar to that of a home (e.g. living room, kitchen, bedroom, and a bathroom). The maximum number of children under family child care services are limited to seven and if greater capacity is required, the operator can apply for group child care or multi-age child care licenses. (BC Ministry of Health, 2008). The intent of this legislation is to ensure that there is a minimum established standard of operations such that the facilities can ensure the health and safety of the children under the facility's care.

\section{Food Premises Regulation}

One of the major inspection programs among the five regional Health Authorities in BC is food inspection at commercial food establishments and kitchens. Under section 2(d.1), the BC FPR applies to assisted living residences that are regulated under the BCCCALA if they are serving more than 6 residences. This piece of legislation allows HA that employ Environmental Health Officers (EHOs) to inspect the kitchen of these facilities, maintain compliance to the BCFPR and take enforcement measures when necessary. EHO performs these inspections to ensure that the kitchens are operating such that contaminated food is not being served. Contamination of food can be a result, but not limited to, improper dishwashing, cross contamination, and improper temperature storage of food (B.C. Laws, 2013b). It is vital that the kitchens are maintaining adequate food handling safety, as community care and assisted living facilities serve largely high-risk population groups that are more susceptible to injury and disease. Food can be a vehicle for communicable disease transmission. As these demographics have weaker immune systems, these infections may have a more severe impact on this population group.

\section{Inspection categories and Violations}

In food premises inspections, the five health authorities classify violations as critical and non-critical. Critical violations are legislated violations where, in the opinion of the health officer, poses an imminent health risk to the 
public. For example, FHA identifies that "food contaminated or unfit for human consumption, food not processed in a manner that makes it safe to eat, and adequate hand washing stations not available for employees" as critical violations. These violations can pose imminent risk to the public and facilitate the spread of communicable diseases thus it is imperative that these violations are immediately remediated (Cseke et al., 2014).

Unlike food premises inspections, community care facility inspections have ten categories of violations as reported by FHA. The first category of violations is "Care and/or supervision." Operators of these facilities must provide adequate supervision of children/resident patients at all times during their care. They must be in a healthy and safe environment. Additionally for residential care facilities, the operator or licensee, must ensure they have an updated plan of care and are following it for each individual. For instance, this plan of care may include oral care, therapeutic instructions, medication administration and activity planning (Fraser Health Authority, 2012; Fraser Health Authority, 2011; Vancouver Coastal Health Authority, n.d.[c]).

The second category of violation is "Hygiene and communicable disease control." The operator must operate at adequate levels of sanitation such that it minimizes the spread of communicable diseases. This includes having adequate hand washing, diapering and toileting control practises (Fraser Health Authority, 2012; Fraser Health Authority, 2011; Vancouver Coastal Health Authority, n.d.[c]).

The third category is "Licensing." This category of violation covers the administrative compliance of the operator. The operator is required to notify the MHO of any changes to the structure and operation of the facility (Fraser Health Authority, 2012; Fraser Health Authority, 2011; Vancouver Coastal Health Authority, n.d.[c]).

The fourth category of violation is "medication" which requires the operator to properly store and administer medication appropriately should a child under their care require medication. With respect to residential care facilities, the operator needs to have proper records and policies on medication administration and proper storage practices such that they comply with the prescribed BC legislations (Fraser Health Authority, 2012; Fraser Health Authority, 2011; Vancouver Coastal Health Authority, n.d.[c]).

"Nutrition and food services" is the fifth category of violations. In a child care setting, the operator is required to encourage and facilitate healthy eating and nutritional habits. They need to provide parents with information in regards to the food provided. In residential care facilities, operators must be storing, preparing and delivering food in a safe manner. As some residents of these facilities may have difficulties consuming solid foods, the operator must ensure there is proper assistance with eating, which may include modifying the texture of the food (Fraser Health Authority, 2012; Fraser Health Authority, 2011; Vancouver Coastal Health Authority, n.d.[c]).

"Physical facility, equipment and furnishings" is the sixth category of violation where operators must ensure that the facility, furniture, and equipment are in good condition, sanitized and do not pose a hazard to the children/residence (Fraser Health Authority, 2012; Fraser Health Authority, 2011; Vancouver Coastal Health Authority, n.d.[c]).

The seventh category is "policies and procedures" where LOs examined the facilities and ensure they have proper policies in place to guide the staff in caring and supervising the children and/or patrons of the facility. LOs examined these policies and ensure they are catered to the needs of children/residence and that the staffs are well aware of these policies and procedures (Fraser Health Authority, 2012; Fraser Health Authority, 2011; Vancouver Coastal Health Authority, n.d.[c]).

The eighth category of violations is "program.” Operators of child care facilities are required have safe, accessible indoor and outdoor recreation areas and activities. Programs in place for these children should be updated and catered to the needs of children. The child care programs need to promote the children's intellectual, physical, social and emotional well-being. Residential care facilities also share similar program criteria. The residence must have easy access to safe indoor and outdoor recreational areas. These programs must be offered to the residence at no additional cost and should consist of a mixture of physical, social and recreational activities (Fraser Health Authority, 2012; Fraser Health Authority, 2011; Vancouver Coastal Health Authority, n.d.[c]).

The ninth category of violations is "Records and reporting”. LOs inspect facilities and ensure that operators are properly keeping records in a manner that is in compliance with the prescribed $\mathrm{BC}$ regulations. These records are used to aid the facility in improving their services such that they are able to provide a healthy and safe environment for the facility's users (Fraser Health Authority, 2012; Fraser Health Authority, 2011; Vancouver Coastal Health Authority, n.d.[c]).

Finally, the last inspection category is "Staffing”. The LO must inspect and assess the facility to have an appropriate number of staff to provide adequate care and supervision. 
These staff members must be appropriately trained. It is important that there is appropriate staff to children/residence ratio to ensure that proper care and supervision (Fraser Health Authority, 2012; Fraser Health Authority, 2011; Vancouver Coastal Health Authority, n.d.[c]).

LOs are also responsible to ensure that operators are in compliance with their license condition. When an inspector finds that the operation is not in compliance with the prescribed legislations, three options are available: placing a condition on the facility's operating license, suspending the license, or canceling the license (Fraser Health Authority, 2012; Fraser Health Authority, 2011; Vancouver Coastal Health Authority, n.d.[c]).

\section{Illness and Injury}

The legislations established in $\mathrm{BC}$ are intended to protect the patron's health and rights in these facilities. Children and elderly individuals are identified to be high risk populations that are at increased risk of illness or injury due to their physiology. In a residential care facility, it has been estimated that 1.7 falls occur per person-year which can result in hip fractures (Rubenstein, 2006). Aside from age, patrons of residential care facilities may have complex health issues, such as advanced dementia, multiple chronic health conditions and limited mobility, which increases their risk of injury (Scott et al., 2010). In addition to the increased risk of injuries, the elderly population is also at an increased risk for contracting infectious diseases. Studies indicate that those in the elderly age demographics do not have as active of an immune system as younger populations (Boraschi et al., 2013; Murphy, 2012). This in turn allows elderly people to be more susceptible to bacterial and viral infections and complications from contracting these infections. In 2013, a norovirus outbreak occurred at a seniors' home in BC where 106 residents fell ill and nine of these individuals died (Luk, 2013). As a patron of these facilities, these individuals may require assistance and monitoring of their everyday activities. However, there should be a balance of protecting those patrons and infringing on their rights. The ten core programs of inspections are present to ensure that there is a minimum standard of care while protect their rights.

Children are also identified to be a high-risk population as they are more susceptible to infections due to their underdeveloped immune system and behavioural differences from adults (e.g. they are more likely to pick up objects and put it into their mouths). Research has shown that children attending out-of-home care had an increased risk of contracting an infectious disease (Gunn et al., 1991). This is likely due to the fact that childcare facilities bring together children who are inertly more susceptible to infection. Children are more likely to put objects in their mouth and less likely to wash their hands. Infectious diseases may produce more severe symptoms or lead to serious complications. A re-emerging concern is where some parents are choosing to not vaccinate their children thus making them vulnerable to preventable diseases. This creates serious public health concern as children can easily carry and spread the disease to other children while at childcare facilities. For instance, in 2014, there were 375 confirmed cases of measles located in the Fraser East region of BC due to resistance to vaccination (Fraser Health, 2014).

The legislations prescribed by the BCCCALA, BCRCR, and BCCCR are established to maintained a minimum standard of operation. As patrons of community care facilities are at higher risk of getting injured or contracting disease, it is important that these facilities are meeting the prescribed legislations. Facilities failing to comply with the above legislations pose increased risk of injuries and illnesses to the users of these facilities.

\section{Aging Population in Canada and British Columbia}

Statistics Canada estimated that the Canadian population is at 35,540,400 as of mid-2014 (Statistics Canada, 2014). Of this population, $15.7 \%$ were reported to be age 65 or older. Projections speculated that in 2016, this population would be greater than the number of people under the age of 15 . Fifty year projections speculates that in 2063, the elderly population will make up $24-28 \%$ of Canada's population. This increase in the aging population and decline in young population has been attributed to longer life expectancy and low fertility levels among Canadians (Statistics Canada, 2014). As the elderly demographic grows, there will be a greater demand for community care and assisted living facilities.

Metcalfe's study recognized that the Metro Vancouver region is aging quickly and also forecasts an increase in demand for residential care facilities. It recognized that home and community care as a cost effective system for addressing the health concerns of this age demographic (Metcalfe, 2013). It is important for the HAs in BC to identify any persistent violation trends in community care and assisted living facilities so that resources can be properly allocated to remediate common and trending violations before it exponentially grows along with the cost of rectifying these violations. Data analysis of violations recorded on inspection reports is therefore helpful in identifying the weakness of the current inspection system and where increased compliance is needed. .

\section{Roles in BC Community Care}

In $\mathrm{BC}$, there are about 6,000 child care and 1,050 adult and child residential facilities that are licensed (BC 
Ministry of Health, n.d.). The responsibility of licensing these facilities are delegated to the five regional health authorities. The LOs are responsible under the BCCCALA and regulations to issue licenses, perform routine monitoring and inspections, respond to and investigate complaints, and investigate unlicensed facility complaints (Fraser Health Authority, n.d.[b]; Vancouver Island Health Authority, n.d.; Interior Health Authority, n.d.[b]; Northern Health Authority, n.d.[a]). Facilities that serve more than six clients are required to receive a health permit for their kitchen and must abide to the BCFPR. Environmental Health Officers (EHOs) employed by the regional HA perform routine inspections and ensure compliance with the established standards in the BCFPR. Ultimately the HAs employ EHOs and LOs to ensure that these facilities are in compliance with the legislated standards to safeguard the health of the users and the public.

\section{METHODS}

\section{Description of standard methods}

The methods utilized in this study were adapted from Cseke et al.'s (2014) research on violations at BC food premises. Violation data were gathered from VCH, FHA, VIHA, IHA, and NHA's website containing the inspection reports for public access. 30 child care and 30 residential care facilities were randomly selected from each HA. Inspection data reports from 2012 to 2015 were extracted and analyzed from each HA. Data was inputted into Microsoft Excel 2013. Microsoft Excel was the primary software used to store, sort, organize, and manipulate the data for descriptive statistical analyses. Data was then extracted and inputted into NCSS for further inferential statistical analysis. A one-way ANOVA analysis was performed to examine the frequency of violations at community care and assisted living facilities and its location among the five regional HAs.

The data withdrawn from the inspection report include: Date of inspection, number of violations, corresponding legislation violations are in contravention of, number of violations in respect to the ten categories of violations, address of facility (street address and city), and capacity of facility (if provided)

\section{Randomized Selection of Data}

The data available for residential care facilities and child care facilities is vast and analysis of all data points was outside of the scope of this project. A subset of this data was randomly selected for analysis. Microsoft Office Excel 2013 was used to generate random numbers.

\section{PURPOSE OF STUDY}

This is the first known study that will be analyzing community care and assisted living facilities' violations. The purpose of this study is to assess violation data of community care facilities among the five regional health authorities responsible by the LO. Violations were analyzed in respect to the ten violation categories: care and/or supervision, hygiene and communicable disease control, licensing, medication, nutrition and food services, physical facilities, equipment and furnishings, policies and procedures, program, records and reporting, and staffing. Violations were tallied and compared among different the five different health authorities to identify if there was a difference in the number of violations and differences in the number of types of violations in the five regional health authorities in BC.

\section{Vancouver Coastal Health}

As of January 1, 2015, child care and residential care facility inspection reports can be accessed at http://www.inspections.vcha.ca/Main. The report type filter were set to "Residential Care" or "Child Care" to access all inspection reports for the respective facility type. Entries were sorted by facility name and the "City Area" was set to "All Areas". These parameters were used to search and filter the inspection reports. After filtering, 71 pages of different child care facilities were produced. Each page contained twenty different facilities and was sorted in alphanumerical order. Random numbers were generated between $1-71$ to randomly select a page number. Another number was generated between $1-20$ to randomly select the facility and inspection data was extracted from this facility. When the parameter was adjusted for "Residential Care", there were ten pages of different residential care facilities with twenty facilities per page. Random selection of inspections were performed identical to VCH Child Care.

\section{Fraser Health}

FHA has their child care facility inspection viewable at http://www.healthspace.ca/fha/childcare. Unlike VCH, FHA organizes their inspections by city. For child care facilities, there were twenty cities that have child care facilities officially inspected by FHA's LO. These cities were placed into a 2x26 array in Microsoft Excel 2013. A random number was generated between 1-26. This number was then used to randomly select a city in FHA. When selecting the city, there may be up to thirty different 
facilities per city per page. Another number was generated between 1-30 to randomly select a facility within a $\mathrm{FH}$ city.

Residential care inspections by FHA can be publically viewed at: http://www.healthspace.ca/fha/rescare. As of January 1, 2015, there were nineteen cities in FHA that have residential care facilities inspected and licensed by FH. Similar to child care facilities in FHA, a 2x19 array was generated in Microsoft Excel 2013. Numbers were generated in Microsoft Excel 2013 to randomly select a city that corresponded with each number.

\section{Interior Health}

IHA organized their child care and residential care facility inspections separately. Data was extracted from https://www.interiorhealth.ca/YourEnvironment/Inspecti onReports/Pages/default.aspx on January 5, 2015. For child care facilities, the report type was adjusted to "Child Care," the region field was set at "All Regions," the facility name field was left blank and entries were sorted by "Facility Name." There were 76 pages of inspection data with ten facilities per page. A random number was generated between 1-76 to randomly select a page for facility selection and another number was randomly generated to select a facility for inspection data extraction. For residential care facilities, the "Report Type" field was adjusted to "Residential Care" and all other fields remained the same as child care. Eighteen pages of facilities were generated with ten entries per page. Randomization of data extraction were perform similarly to child care.

\section{Vancouver Island and Northern Health}

VIHA and NHA did not separate their inspections for child care and residential care facilities. To filter out child care facilities, on the search bar, "child" was entered to filter out the child care facilities. The names of the child care facilities were all copied into a spread sheet in Microsoft Excel 2013 and was sorted alphanumerically. A second column was numbered from one down to the number of facilities identified. Thirty random numbers were generated that correspond with a unique facility. These facilities were selected for inspection report data extraction. A similar approach was performed for residential care facilities in VIHA and $\mathrm{NH}$. In the search bar, "residential" was entered and used to filter out all residential care facilities.

\section{Reliability and Validity of Measures}

Reliability of the results were increased by the usage of validated, licensed software. Microsoft Excel and NCSS statistical analysis software are commercially available software that have been validated before being made available for users. Freeware alternatives such as PSPP may not have the same validation as the tools have been generated as a freeware option. There may not have been a quality check to reassure that the software is functioning as it is designed.

One component of this research that may decrease the reliability is how different inspectors may perform their inspection differently. Some inspectors may look out for more specific components of the violations that they subjectively decide to be more important during inspections. Furthermore, each inspector may fill out the inspection forms differently thus affecting the reliability of the results. Two inspectors performing the same inspection may generate two different inspection reports. In addition, this study was conducted to compare violation data between different health authority regions which may have different policies and municipal bylaws that may affect how inspections are performed and what constitutes as a violation. To minimize this, only inspection reports dated January 2012 to January 2015 were examined to minimize any chances of policy changes or new bylaws taking into effect among the regions. Investigations were performed at identifying the violations that are in contravention to the provincial legislations as each facility must abide to this piece of legislation.

The internal validity of study was mostly applicable to British Columbia. All HAs performed their inspections based on the ten categories of violations and these violations correspond to the provincial legislation. This study had very little or no external validity to other provinces in Canada or be applied to other countries. Each Canadian province may have different legislations governing how community care and assisted living facilities should operate and this will greatly differ among countries.

\section{Inclusion and Exclusion Criteria}

Only data from the HAs' public website were used in this analysis. As these HAs have reported on their website, not all inspection reports are posted online. Furthermore, certain HAs perform non-visit follow-up inspections, these inspections were not used to tabulate violation data (Northern Health, n.d.[b], Vancouver Coastal Health, n.d.[d]). Violation data were gathered from VCH, FHA, IHA, VIHA and NHA. The inspection reports that were analyzed include only routine and follow-up inspections. Some inspection reports reported by FHA in 2012 reported violations as "codes" rather than contraventions to the regulations. These inspection reports were excluded to maintain consistency with the rest of the data collected.

\section{Ethical Considerations}

The data used is publically available on the respective health authority's website. However, caution was taken to avoid slandering specific facilities. Names of the facilities 
used in the data analysis were not recorded and were not vital to the interpretation of the study.

\section{STATISTICAL ANALYSIS}

\section{Descriptive statistics}

Data obtained from the five different BC HAs included the number of different violations to the ten inspection category criteria. Table 3 summarizes the violation data found in the child care facilities. It was found that IHA had the highest average of 6.03 violations per inspection with a total of 452 violations found in the 75 inspection reports extracted between January 2012 to January 2015. NHA was found to have the lowest average of violations with 0.888 violations per inspection. It was also found that
NHA had the lowest number of violations found with 71 total violations identified from the sample of 80 inspection reports.

Table 3 summarizes the breakdown of violations in respect to child care facilities and the ten inspection categories. Many of VCH and FH's violations were in the categories: physical facility, equipment and furnishings, records and reporting, and staffing. Facilities in IHA also had most of their violations in these categories but also had many policies and procedures violations. Facilities in VIHA had violations mainly in records and reporting, and staffing. NHA had very few violations with most of the violations categorized in staffing.

Table 3: Descriptive summary analysis of child care facility inspections and their violations

\begin{tabular}{|c|c|c|c|c|c|}
\hline & $\mathrm{VCH}$ & FHA & IHA & VIHA & NHA \\
\hline \# of facilities examined & 30 & 30 & 30 & 30 & 30 \\
\hline $\begin{array}{l}\text { \# of inspections } \\
\text { analyzed between Jan. } \\
2012 \text { - Jan. } 2015\end{array}$ & 75 & 84 & 75 & 94 & 80 \\
\hline $\begin{array}{l}\text { Mean number of } \\
\text { violations per } \\
\text { inspection }\end{array}$ & 1.31 & 2.93 & 6.03 & 2.46 & 0.888 \\
\hline $\begin{array}{l}\text { Total Number of } \\
\text { violations }\end{array}$ & 98 & 246 & 452 & 232 & 71 \\
\hline $\begin{array}{l}\text { Median Number of } \\
\text { Violations }\end{array}$ & 0 & 2 & 5 & 2 & 0 \\
\hline $\begin{array}{l}\text { Mode number of } \\
\text { violations }\end{array}$ & 0 & 0 & 2 & 0 & 0 \\
\hline Range & 12 & 14 & 24 & 12 & 14 \\
\hline Standard Deviation & 2.22 & 3.26 & 5.16 & 2.84 & 1.94 \\
\hline
\end{tabular}

Table 4: Descriptive summary of violation data of child care facilities among the five health authorities

\begin{tabular}{|c|c|c|c|c|c|}
\hline & VCH & FHA & IHA & VIHA & NHA \\
\hline Ten Categories of inspection & & & & & \\
\hline Care and/or supervision & 3 & 4 & 16 & 22 & 3 \\
\hline Hygiene and communicable disease control & 3 & 4 & 12 & 0 & 0 \\
\hline Licensing & 2 & 8 & 5 & 4 & 0 \\
\hline Medication & 0 & 4 & 2 & 0 & 0 \\
\hline Nutrition and food services & 1 & 9 & 0 & 2 & 2 \\
\hline Physical facility, equipment and furnishings & 36 & 46 & 85 & 27 & 12 \\
\hline Policies and procedures & 1 & 15 & 105 & 17 & 2 \\
\hline Program & 0 & 2 & 1 & 0 & 1 \\
\hline Records and reporting & 24 & 75 & 119 & 70 & 18 \\
\hline Staffing & 25 & 70 & 61 & 57 & 25 \\
\hline General Requirements $^{1}$ & 3 & - & - & - & - \\
\hline
\end{tabular}




\begin{tabular}{l|rrrrr} 
DLSOP Safe Play Space $^{2}$ & - & 3 & - & 33 & 8 \\
\hline Structure, Maintenance, Operation $^{3}$ & - & - & 29 & - \\
\hline Total & 98 & 246 & 452 & 232
\end{tabular}

${ }^{1} \mathrm{VCH}$ reported some violations as “General Requirements”

${ }^{2}$ DLSOP - Director of Licensing Standards of Practice Safe Play Space are extra policies and standards that child care facilities are abide to by law. This is an additional violation category.

${ }^{3}$ Structure, Maintenance, Operations was a unique violation category IHA used for some of their violations.

Table 4 summarizes the descriptive statistics of violations in child care facilities. It shared similar trends with child care facilities with IHA facilities having the most violations and NHA having the lowest number of violations. IHA had an average of 9.89 violations per inspections and NHA with an average 0.72 violations per inspection. IHA also had the highest number of violations with 811 tallied from 82 inspection reports.

Table 5 summarizes the distribution of violations found in residential care facilities. Many of the violations found in $\mathrm{VCH}$ residential care facilities were physical facility, equipment and furnishings. Many violations found in FHA were physical facility, equipment and furnishings, policies and procedures, and staffing. IHA facilities had many violations in general. It also had many violations in physical facility, equipment and furnishings. However, IHA facilities also had high numbers of violations in care and/or supervision, hygiene and communicable disease control, medication, nutrition and food services, policies and procedures, and records and reporting. Residential care facilities had high number of violations in care and/or supervision and policies procedures. NHA facilities had the lowest number of violations with majority of them being physical facility, equipment and furnishings.

Table 5: Descriptive summary analysis of residential care facility inspections and their violations

\begin{tabular}{|c|c|c|c|c|c|}
\hline & VCH & FHA & IHA & VIHA & NHA \\
\hline \# of facilities examined & 31 & 30 & 30 & 30 & 30 \\
\hline $\begin{array}{l}\text { \# of inspections } \\
\text { analyzed between Jan. } \\
\text { 2012 - Jan. } 2015\end{array}$ & 121 & 79 & 82 & 116 & 85 \\
\hline $\begin{array}{l}\text { Mean number of } \\
\text { violations per } \\
\text { inspection }\end{array}$ & 2.14 & 5.23 & 9.89 & 3.08 & 0.72 \\
\hline $\begin{array}{l}\text { Total Number of } \\
\text { violations }\end{array}$ & 259 & 413 & 811 & 357 & 61 \\
\hline $\begin{array}{l}\text { Median Number of } \\
\text { Violations }\end{array}$ & 1 & 3 & 10 & 2 & 0 \\
\hline $\begin{array}{l}\text { Mode number of } \\
\text { violations }\end{array}$ & 0 & 0 & 14 & 0 & 0 \\
\hline Range & 14 & 27 & 31 & 27 & 4 \\
\hline Standard Deviation & 2.71 & 6.07 & 5.53 & 3.78 & 1.11 \\
\hline
\end{tabular}

Table 6: Descriptive summary of violation data of residential care facilities among the five health authorities

\begin{tabular}{l|rrrrr}
\multicolumn{1}{l}{} & VCH & FHA & IHA & VIHA & NHA \\
\cline { 1 - 1 } Ten Categories of inspection & & & & & \\
\cline { 1 - 3 } Care and/or supervision & 46 & 39 & 91 & 67 & 1 \\
Hygiene and communicable disease control & 7 & 27 & 72 & 30 & 5
\end{tabular}




\begin{tabular}{|c|c|c|c|c|c|}
\hline Licensing & 14 & 9 & 9 & 11 & 1 \\
\hline Medication & 20 & 15 & 78 & 23 & 2 \\
\hline Nutrition and food services & 22 & 10 & 65 & 20 & 4 \\
\hline Physical facility, equipment and furnishings & 80 & 83 & 262 & 52 & 34 \\
\hline Policies and procedures & 16 & 94 & 79 & 71 & 1 \\
\hline Program & 1 & 0 & 2 & 1 & 0 \\
\hline Records and reporting & 43 & 56 & 103 & 46 & 6 \\
\hline Staffing & 10 & 76 & 49 & 36 & 7 \\
\hline Additional CCALA $^{1}$ & - & 4 & - & - & - \\
\hline Other $^{2}$ & - & - & 1 & - & - \\
\hline Total & 259 & 413 & 811 & 357 & 61 \\
\hline
\end{tabular}

\section{Inferential Statistics}

The study's hypotheses were:

$\mathbf{H}_{\mathbf{0}}$ : There was no difference in number violations among the child care facilities between health authority regions. $\mathbf{H}_{\mathbf{a}}$ : There was a difference in number of violations among the child care facilities between the health authority regions.

A one-way ANOVA analysis (Heacock \& Sidhu, 2014) was used to compare the violations identified and extracted from the online inspection reports among the different HA regions. This research compared the number of violations among the different regions to identify any discrepancies. It investigated if there were more violations in one health authority compare to another.

\section{Statistical Package}

This study used Microsoft Excel 2013 to perform descriptive analysis of the violation data. Mean, mode, median, range, standard deviation were generated using this software (Microsoft Office 2013 Professional Plus, 2013). The data was exported into NCSS 9 for inferential analysis using a one-way ANOVA analysis to compare the occurrence of violations at a facility and its relation to which HA region the facility is located in (NCSS: Statistical \& Power Analysis Software, 2007).

Table 7: Inferential, one-way ANOVA analysis of violation data among child care facilities located in the five BC health authority regions.

$\begin{array}{lll}\text { Inferential Test } & \begin{array}{l}\text { P-Value (Corrected for } \\ \text { Ties) }\end{array} & \text { Result }(\boldsymbol{\alpha}=\mathbf{0 . 0 5}) \\ \text { ANOVA (Kruskal Wallis) } & 0.005599 & \text { Reject } H_{0}\end{array}$

\section{Interpretation}

Inferential statistical analysis of child care facility violations identified $\mathrm{p}$-value of 0.000000 was obtained thus the null hypothesis is rejected and the alternate hypothesis is accepted. This study concluded there was a statistical significant difference in the number of violations found in child care facilities among the five BC HA regions.

Similarly, inferential statistical analysis of residential care facility violations produced a p-value of 0.000000 . This study concluded there was a statistical difference in the number of violations found in residential care facilities among the five $\mathrm{BC} \mathrm{HA}$ regions.
Post-hoc analysis of child care violations revealed the number of violations in FHA differed from IHA, NHA, and $\mathrm{VCH}$. The number of violations in IHA differed from the four remaining BC HAs. The number of violations in NHA differed from FHA, IHA, and VIHA. There were no differences in violations between NHA and VCH. The number of violations in VIHA differed from IHA and NHA. Violations in VCH facilities differed from facilities in FHA and IHA.

Post-hoc analysis of residential care violations revealed similar results to child care violations. Violations in residential care facilities in IHA differed from all other BC HAs. Violations in NHA facilities also differed with 
facilities in FHA, IHA, and VIHA. However, unlike child care facilities, violations in $\mathrm{VCH}$ residential care facilities differed from facilities in FHA and IHA. Additionally, violations in VIHA differs also from facilities in NHA, as well as FHA, and IHA.

\section{DISCUSSION}

The purpose of this study was to determine if there were any differences among the number of violations in child care and residential care facilities among the five different BC HAs. As such, it was identified that there was a difference in the number of violations in both child care and residential care facilities among the five BC HAs.

\section{Child Care Facilities}

Among the samples collected, IHA presented with the highest number of violations compared the other BC HAs. It can be interpreted that because the IHA facilities do not meet the established legislatively prescribed standards, children attending these facilities may be at an increased risk of injury or illness. Hence, there may be a greater potential for injury or illness at a child facility located in the IHA. In contrast, child care facilities found in the NHA had the lowest number of violations per inspection. Patrons and workers of these facilities may be less likely to become injured or ill.

CBC News reported 120 child care facilities (30\% of all child care facilities) in Nova Scotia each had over ten violations for the past two years. Using information obtained from the Freedom of Information Act, the following were identified to be the ten most frequent violations (Tunney, 2014):

1. Not performing/finishing child abuse registry checks on employees

2. Not having valid first aid and CPR training

3. Not abiding to the guideline practises for preventing and controlling communicable diseases

4. Lack of recordkeeping of immunization information on children's files

5. Not performing/finishing criminal record checks on workers

6. Preschooler and school age children-designed toys were not being cleaned at appropriate frequencies

7. Children were not provided with one or more outdoor safe play spaces

8. Facilities did not have documented written parental consent

9. Parent handbook was not in a visible location

10. Infant and toddler-designed toys were not cleaned at appropriate frequencies
In this study, Record and Reporting was the predominant violation category among the five BC HAs. As identified above, (4) and (8) coincide with the findings in BC. Furthermore, staffing violations were identified to be common violations which corresponds with (1), (2), \& (5). These frequent categories of violations shared in BC and Nova Scotia could be indicative that there may be certain violations that occur more frequently in child care facilities across Canada. LOs and other health professionals across Canada may need to place stronger emphasis on identifying and remediating these types of violations. However, the findings are still relatively new and there is a lack of research on the various types of violations in child care facilities and implications on the clients of those facilities.

In contrast, while BC had very few hygiene and communicable disease control violations, Nova Scotia had more of these violations as highlighted by violation (3), (6), and (10). Even though there may have been shared differences between the two provinces, the variation in the types of violations could be a result of regional, cultural and population differences. In addition, this could be an indication there may be different legislative standards among the two provinces or there are different focuses among the different provincial health agencies that govern child care facilities.

\section{Residential Care Facilities}

Similar to child care facilities in BC, IHA residential care facilities had the highest number of violations per inspection compared to the other provincial HAs. It is suggested that patrons of these facilities may have a higher chance of becoming injured or ill as these facilities fail to meet the legislatively prescribed standards in BC. In contrast, residential care facilities located in NHA were found to have the lowest number of violations per inspections. This corresponded with the findings in child care facilities. Similarly, these findings suggested that patrons are less likely to get injured or ill at facilities located in NHA.

The Hamilton Spectator reported a residential care facility failing to comply for three years. These problems included pest infestation of rodents and bed bugs, inadequately trained staff, and poor recordkeeping. It was reported that these problems persisted for three years before the facility was eventually closed by the city (Reilly, 2012). These findings corresponded very well with the research conducted in this study. Physical facility, equipment and furnishing, staffing, and records and reporting violations occurred very frequently in BC facilities. These could be indicative of common problems and violations found among all Canadian residential care 
facilities. Unfortunately, this comparison is limited to the report made by Reilly (2012). Further investigation is required to identify other common residential care violations found in Hamilton, Ontario. While there are commonalities found Reilly's report (2012) and this study, there may also be differences in the types of violations found between the two regions as highlighted in childcare facilities.

\section{Limitations}

A limitation of this study is that while each of the five BC health authorities are inspecting and auditing childcare and residential care facilities towards the same legislations, inconsistencies may still arise. Each health authority region has different policies in regards to how a LO should conduct their inspection of a residential and childcare facilities. This may be a reason for why there is a discrepancy in the number of violations per health authority region. In addition, each LO could have a different "style" in their conduction of an inspection. For instance, one LO may place further emphasis on inspecting for Care and Supervision violations while another LO may not place as much effort in looking for these types of violations.

Another limitation that should be noted is that while IHA was sampled to have the most violations, it may be a result of IHA having a better or stricter inspection program. IHA's LOs may also be better trained in these inspections thus more competent at identifying violations during inspections.

It should be noted that this study only illustrated that certain HAs have facilities with higher number of violations per inspections. There is no indication that these facilities also have higher incidences of injuries or illnesses. However, the legislative standards are prescribed with the intent to reduce the overall risk of these incidences from occurring. It logically follows that facilities with higher number of violations are below the established standard. Therefore, the patrons of these facilities are at greater risk of getting injured or ill.

Comparisons made in this study were compared with news reports. There may be inaccuracies to these news reports as they are not peer-reviewed. Further studies are required to assess the distribution of violations across the country and how they compare from health authority to health authority and from province to province.

The demographic of each region is very likely to influence the number of violations/inspection found in each region. For instance, areas with larger populations of elderly people will likely to have more residential care facilities. This has two implications. It would mean that one region may be responsible for regulating more facilities per given geographical area. As a result, there may be a lack of resources that can fund regular inspection and enforcement of these facilities. Secondly, if there is a greater distribution of elderly people or children in a certain region, there should be more efforts in working with the child care and residential care facilities to compliance with the legislation. This study was not able to account for demographic or socio-economic factors that may have influenced the distribution of violations in each care facility among the five BC HAs.

\section{Future Studies:}

One follow-up study that could be conducted would be to examine if facilities with high number of violations will have high incidences of illness or injuries at the facilities. This study could be conducted to identify if there is an association between facilities with high numbers of violations and the incidences of illnesses and injuries.

Certain health authorities report which EHO/LO performed the inspection and filled out the inspection form. Future examination should investigate to identify if a bias truly exists among the various EHOs. A study can be conducted to evaluate what violations are commonly identified by the $\mathrm{EHO} / \mathrm{LO}$. This can be compared among EHOs and LOs to identify if certain inspectors report more violations than others.

In BC, child care and residential care facilities that house more than six patrons and have a kitchen are required to have an operating permit from the HA. The kitchen would be inspected by the EHO. A study may be conducted to identify the number of critical and non-critical violations. This can be compared with the inspection made by the LO to identify if facilities with higher number of violations will also have higher number of critical violations in their kitchen operations. Food is a major vehicle for transferring pathogens. As children and the elderly population are known to be at higher risk of injury or illness, proper food handling is required to reduce the risk of transferring pathogens to these individuals.

Further studies should investigate other Canadian provinces and territories to identify how child care and residential care facilities are regulated. Violations can be tallied and comparisons can be made among the different provinces and territories. Common types of violations can be identified throughout Canada. Furthermore, it will identify what types of violations are most prominent in each region. Regulating agencies will be able to appropriately allocate their resources in remediating these violations.

As identified in the previous section, socio-economic and demographic distribution patterns are very likely to 
contribute to how violations are distributed among the facilities located in each HA. It is recommended that a follow-up study is conducted to analyze the patterns of violations in each $\mathrm{HA}$ and compare that to demographic and socio-economic patterns of each HA region.

\section{CONCLUSIONS:}

Children and elderly people are more susceptible to becoming ill or injured than a healthy adult population. Child care and residential care facilities bring together these high risk individuals. As a result, this could increase the likelihood of disease transmission. Conversely, the environment of these facilities may also pose a physical risk to these individuals. As such, these facilities are legislatively required to meet the standards prescribed to minimize these risks. In this study, IHA was identified to have the most violations among the five BC health authorities in both their child care and residential care facilities. As these facilities do meet the provincial standards, there is a higher potential of illness or injury for the patrons are attending these facilities located in the IHA. In contrast, NHA was identified to have the fewest number of violations in both their child care and residential care facilities. There is a less likelihood of injury or illness to the patrons attending these facilities located in NHA.

\section{RECOMMENDATIONS:}

The study conducted identified violations in child and residential care facilities that may pose an increased risk to the patrons of these facilities. Based on the results of this study, inspections of facilities with higher numbers of violations (i.e. IHA) should be conducted with heavier emphasis on education and enforcement actions should be considered to improve overall compliance the legislative requirements. It is recommended that these health authorities allocate or reallocate resources into working with these facilities to increase compliance. Secondly, it is uncertain whether these facilities began their operations poorly or if they were initially in compliance with the regulations and gradually devolved out of compliance. New facilities should be licensed only with confidence that operators are capable of maintaining the standard of care required. New operators should be required to have long-term business and financial plans to ensure that the quality of care is maintained but also allow for continued maintenance of their establishment

\section{ACKNOWLEDGEMENTS:}

This study was conducted with the aid from Helen Heacock (supervisor), Bobby Sidhu (BCIT instructor), and Lorraine McIntyre (BCCDC contributor).

\section{COMPETING INTERESTS:}

There were no competing interests during the conduction of this study.

\section{REFERENCES:}

B.C. Laws. (2013a). Child care licensing regulation B.C. Reg. 205/2013. (C) Queen's Printer. Victoria, B.C. Retrieved from: http://www.bclaws.ca/civix/document/id/comple te/statreg/332_2007

B.C. Laws. (2013b). Food Premises Regulation B.C. Reg. 59/2013. (C) Queen’s Printer. Victoria, B.C. Retrieved from: http://www.bclaws.ca/civix/document/id/comple te/statreg/210_99

B.C. Laws (2013c). Residential care regulation B.C. Reg. 205/2013. (C) Queen's Printer. Victoria. B.C.

Retrieved from: http://www.bclaws.ca/civix/document/id/comple te/statreg/96_2009

B.C. Laws (2008). Community care and assisted living regulation B.C. Reg. 324/2008. (C) Queen's Printer. Victoria, B.C. Retrieved from: http://www.bclaws.ca/civix/document/id/comple te/statreg/217_2004

B.C. Laws. (2002). Community care and assisted living act. (c) Queen's Printer. Victoria, B.C. Retrieved from:

http://www.bclaws.ca/civix/document/id/comple te/statreg/02075_01

BC Ministry of Health. (2008, July 9). Director of licensing standards of practice family child care. Retrieved from: http://www.health.gov.bc.ca/ccf/pdf/SoP_Family _Child_Care.pdf

BC Ministry of Health. (2007, December 10). Director of licensing standards of practice safe play space. Retrieved from: http://www.health.gov.bc.ca/ccf/pdf/Safe_Play_ Space.pdf

BC Ministry of Health. (n.d.). Community care licensing. Retrieved from: http://www.health.gov.bc.ca/ccf/

Boraschi, D., Aguado, M., Dutel, C., Goronzy, J., Louis, J., Brubeck-Loebenstein, B., Rappuoli, R., Del Giudice, G. (2013, May 15). The gracefully aging immune system. Science Translational 
Magazine 5(185), 1-9. doi:

10.1126/scitranslmed.3005624

Cseke, P., Heacock, H., Sidhu, B., McIntyre, L., Wilcott, L. (2014). Inspecting inspection reports, does the type of restaurant change the risk?. Retrieved from:

http://contentpro.lib.bcit.ca/iii/cpro/app?id=2536 882354601455\&itemId=1005129\&lang=eng\&se rvice $=$ blob\&suite $=$ def

GNU PSPP. (2014). Accessed on November 2014. Website: http://www.gnu.org/software/pspp/

Gunn, W., Pinsky, P., Sacks, J., Schonberger, L. (1991, July). Injuries and poisonings in out-of-home child care and home care. Am J Dis Child. 145(7):773-778. doi:10.1001/archpedi.1991.02160070075025.

Fraser Health Authority. (2014, April 8). Health alert: measles in fraser east. Retrieved from: http://www.fraserhealth.ca/your_health/immuniz ations/measles/news-and-updates/

Fraser Health Authority. (2012, September 7). Inspection category definitions: violation categories.

Retrieved from: http://www.fraserhealth.ca/media/CCFL_Inspect ionCategories.pdf

Fraser Health Authority. (2011, March 7). Violation categories. Retrieved from: http://www.healthspace.ca/Clients/FHA/FHA_ Website.nsf/CCFL-Adult-Violations

Fraser Health. (n.d.[a]). Child care facilities. Retrieved from: http://www.healthspace.ca/fha/childcare

Fraser Health Authority. (n.d.[b]). Community care facilities licensing. Retrieved from: http://www.fraserhealth.ca/your environment/cc $\underline{\mathrm{fl} l}$

Heacock, H. \& Sidhu, B. (2014) Research methods module 5: descriptive statistics. BCIT ENVH 8400 - Research Methods Course Notes.

Interior Health. (n.d.[a]). Inspection reports. Retrieved from: https://www.interiorhealth.ca/yourenvironment/i nspectionreports/Pages/default.aspx

Interior Health Authority. (n.d.[b]). Residential care facilities. Retrieved from: https://www.interiorhealth.ca/YourEnvironment/ ResidentialCareFacilities/Pages/default.aspx
Luk, V. (2013, July 31). Nine dead, 150 sick after 'unusually' fast-spreading norovirus outbreak at b.c. seniors' home. The National Post. Retrieved from:

http://news.nationalpost.com/2013/07/31/ninedead-after-unusual-norovirus-outbreak-at-b-ccare-home-chief-medical-officer/

Metcalfe, S. (2013). Aging community, changing care: a preliminary report on the community-based system of care for seniors in the lower mainland, sea-to-sky corridor and sunshine coast.

Retrieved from:

http://www.uwlm.ca/sites/default/files/webfm/O ur\%20Work/Reports\%20and\%20Resources/CII \%20Reports/Seniors-Care-Report-January2013.pdf

Microsoft Office Professional Plus (2013). Microsoft Excel (Version 2013). Microsoft Corporation.

Murphy, K. (2012). Janeway's immunobiology (8th ed.). New York: New York.

NCSS: Statistical \& Power Analysis Software. (2007). Accessed November 12, 2014. Website: http://www.ncss.com

Northern Health Authority. (n.d.[a]). Community care licensing. Retrieved from:

http://www.northernhealth.ca/YourHealth/Com munityCareLicensing.aspx

Northern Health. (n.d.[b]). Northern Health Public Health Protection. Retrieved from: http://www.healthspace.ca/nha

Reilly, E. (2012, November 27). Host of issues closed residential care facility. Retrieved from: http://www.thespec.com/news-story/2263133host-of-issues-closed-residential-care-facility/

Rubenstein, L.Z. (2006). Falls in older people: epidemiology, risk factors and strategies for prevention. Age \& Aging, 35(Suppl2), ii37-41.

Scott, V., Higginson, A., Sum, A., \& Metcalfe, S. (2010). Falls and related injuries in residential care: a framework and toolkit for prevention. Vancouver, BC: Centre for Excellence for Mobility, Fall Prevention and Injury in Aging, Centre for Hip Health and Mobility.

Statistics Canada. (2014, September 26). Canada's population estimates: age and sex, 2014. Retrieved from: http://www.statcan.gc.ca/dailyquotidien/140926/dq140926b-eng.htm?HPA 
Tunney, C. (2014, December 23). Nova scotia daycares rack up thousands of violations. Retrieved from: http://www.cbc.ca/news/canada/novascotia/nova-scotia-daycares-rack-up-thousandsof-violations-1.2881554

Vancouver Costal Health Authority. (n.d.[a]). Child care a license is required for all facilities caring for three or more children. Retrieved from: https://www.vch.ca/your_environment/facility_li censing/child_care/

Vancouver Coastal Health Authority. (n.d.[b]). Inspection reports: licensing officers regularly inspect residential care facilities. Retrieved from:

https://www.vch.ca/your_environment/facility_li censing/residential-care/inspection-reports/
Vancouver Coastal Health Authority. (n.d.[c]). Child care category definitions. Retrieved from: https://www.vch.ca/media/VCH-child-carefacilities-inspection-reports-categorydeffinitions.pdf

Vancouver Coastal Health. (n.d.[d]). Welcome to vancouver coastal health's inspection reports website. Retrieved from:

http://www.inspections.vcha.ca/

Vancouver Island Health Authority. (n.d.[a]). Inspections. Retrieved from: http://www.viha.ca/mho/inspections/

Vancouver Island Health. (n.d.[b]). Community care facilities. Retrieved from:

www.healthspace.ca/Clients/VIHA/VIHA_Webs ite.nsf/CCFL-Frameset 